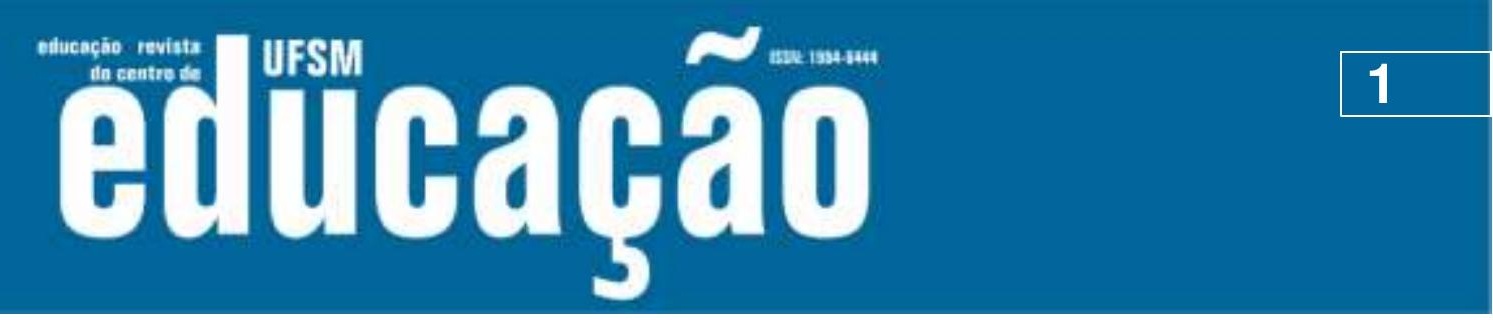

ISSN: 1984-6444 | http://dx.doi.org/10.5902/1984644434189

\title{
Perfil do professor mediador: proposta de identificação
}

\author{
Profile of the mediating teacher: identification proposal
}

Miriam Bastos Reis Maia Lima

Instituto Federal do Amazonas

Elaine Maria Bessa Rebello Guerreiro

Instituto Federal do Amazonas

\section{RESUMO}

Este trabalho originou-se do desenvolvimento de um Produto Acadêmico, necessário para a conclusão do mestrado profissional da autora principal, e objetivou a construção de uma ferramenta que auxilie na identificação do perfil do professor mediador. Trata-se de uma pesquisa de natureza quanti-qualitativa a partir de uma abordagem descritiva. A fundamentação teórica aborda a Pedagogia da Mediação, a Experiência de Aprendizagem Mediada (EAM) e o perfil do professor mediador. A pesquisa partiu dos estudos de Vygotsky sobre a zona de desenvolvimento proximal (ZDP), do paradigma de Feuerstein, concernente ao perfil do professor mediador e da proposta didática cognitivo-construtivista, cujo foco foi identificar as competências didáticas que são demandadas do professor, enquanto mediador do processo ensino/aprendizagem. Com estes fundamentos, foi construído um instrumento de avaliação denominado ProfMed, o qual pode ser utilizado em qualquer nível ou modalidade de ensino. $\mathrm{O}$ instrumento consiste em um questionário semiestruturado dividido em três partes: a primeira refere-se às competências do professor mediador e o grau de concordância do respondente às sentenças apresentadas; a segunda consiste em duas perguntas abertas sobre a prática docente; e a terceira, dos dados gerais do respondente. Neste artigo trataremos apenas da primeira parte citada, que se limita a mensurar o nível de mediação didática do professor com base nas respostas dadas. Esta mensuração não tem a intenção de assumir um caráter de teste, onde alguém seria aprovado ou reprovado, mas um instrumento de reflexão da prática didática com indicativos de áreas a serem trabalhadas através da formação contínua.

Palavras-chave: Mediação; Avaliação; Professor mediador.

\section{ABSTRACT}

This work originated from the development of an Academic Product, necessary for the completion of the main author's professional master's degree, and aimed at the construction of a tool that helps in the identification of the profile of the mediating teacher. It is a quantitative-qualitative research based on a descriptive approach. The 


\section{Lusm oittrabat}

ISSN: 1984-6444 | http://dx.doi.org/10.5902/1984644434189

processo ensino/aprendizagem. De fato, há diversos pontos comuns, entre a teoria de Vygotsky e a de Feuerstein, tais como o reconhecimento do valor da relação social no processo de ensino e aprendizagem. Quanto à história pessoal e profissional, ambos eram de origem judaica, usufruíram de uma educação aprimorada e trabalharam com crianças com deficiência (SOUZA; DEPRESBITERIS; MACHADO, 2003).

O estudo nos forneceu elementos para construção do questionário sobre as práticas didáticas que caracterizam o professor mediador. No processo de avaliação e validação deste instrumento, o mesmo foi submetido a julgamento por um grupo de especialistas em Psicometria e linguística e a um pré-teste com um grupo de docentes de diversos níveis e modalidades de ensino. Neste artigo apresentaremos o resultado, deste estudo, o qual deu origem ao instrumento que denominamos de ProfMed.

\section{Perfil do professor mediador}

Em um processo histórico de delegação e compartilhamento da tarefa educativa, as escolas surgiram como um local e um espaço onde ocorre o processo de ensino e aprendizagem, ministrada por profissionais da educação. Logo, mediar o processo de aprendizagem do aluno é eminentemente o papel do professor, especialmente no espaço formal escolar. Fazendo inferência a Vygotsky, Rego (1995) salienta que o papel distintivo desempenhado pela escola, ao propiciar o ambiente com a finalidade específica, é a de apropriação pelo sujeito da experiência culturalmente acumulada.

A tecnologia avança em uma velocidade maior que a agilidade do sistema em transformar-se para atender às novas demandas. Mas para Demo (2008, p.13) "o professor continua sendo a melhor tecnologia em sala de aula", ele é o profissional que medeia o processo de aprendizagem do aluno, favorecendo-o através de seu saber, por meio da implantação de práticas educativas concatenadas com as demandas educacionais pós-sociedade informacional. E para Moita (1995, p. 15)

"Professores com práticas didáticas efetivas influenciam positivamente na formação dos estudantes, pois ninguém se forma no vazio, porém, o processo de formação supõe troca, experiência, interações sociais, aprendizagens, um sem fim de relações".

A arte de formar professores está e se dá no continuum do processo de formação do professor formador, e neste complexo contexto em que se dá essa 


\section{Lusm Autrabato}

ISSN: 1984-6444 | http://dx.doi.org/10.5902/1984644434189

formação, reside a riqueza deste conhecimento, pois "o próprio educador é a principal ferramenta de seu trabalho e agente principal de sua formação" (MOITA, 1995, p.114).

Para Feuerstein, o criador da teoria da experiência da aprendizagem mediada e da teoria da modificabilidade cognitiva estrutural, a maioria das pessoas apresenta uma série de "funções cognitivas deficientes" (FUEURSTEIN; FUEURSTEIN; FALIK, 2014, p.175), ou seja, os processos mentais muito raramente operam em um ótimo nível de funcionamento. Contudo, a partir de uma avaliação cognitiva adequada e com o auxílio de instrumentos concretos de apoio psicopedagógico, boa parte dos seres humanos torna-se capaz de desenvolver suas potencialidades.

Tomando como base a importância de uma avaliação cognitiva adequada, Tébar (2011) percebeu que a metodologia subjacente ao programa de enriquecimento instrumental (PEI) fornecia contribuições didáticas e metodológicas que favoreciam a prática docente mediadora. O PEI "é um sistema de intervenção constituído a partir de instrumentos para melhorar o funcionamento das funções cognitivas" (CORREA, 2009, p. 47) cuja proposta didática parte do marco teórico sobre a modificabilidade cognitiva estrutural (MCE) e a experiência mediada (EAM), em outras palavras, a estrutura cognitiva tem plasticidade, é modificável e a experiência mediada favorece a sua modificação. Embora o PEI tenha sido desenvolvido por Feuerstein para ser aplicado a pessoas com desmotivação para o estudo, problemas de memória, baixo rendimento escolar e dificuldades de aprendizagem, hiperatividade, dificuldades de atenção, síndrome de Down, dificuldades de raciocínio e abstração, desordens perceptivas, entre outros (CORREA, 2009,), pode ser aplicado a todas as pessoas, independentemente da idade, nível de escolaridade ou experiência profissional, e que necessitem desenvolver seu potencial cognitivo.

\section{Pedagogia da Mediação}

Neste trabalho o conceito de mediação é definido a partir das teorias de Feuerstein, ou seja, o foco da pesquisa não é a "mediação comunicacional" (PRIMO, 2011, p.54) favorecida pelos avanços tecnológicos; tampouco a atuação do professor como mediador em situações de conflito no ambiente escolar; nem o professor que 


\title{
Us:

ISSN: 1984-6444 | http://dx.doi.org/10.5902/1984644434189

atua diretamente com alunos com necessidades especiais. Trata-se da atuação humana imbuída da intencionalidade da aprendizagem. No processo de mediação aquilo que é inato no indivíduo, interage dialeticamente na relação social com o mediador e o meio em um processo intencional de transmissão cultural, de construções de aprendizagens.

Todo ser humano tem um potencial cognitivo que lhe permite ir além, conhecer mais, aprender e criar a partir dos novos conhecimentos adquiridos que interagirão com o que ele já sabe. Neste contexto, a função docente é mediar o processo de aprendizagem atuando na ZDP, criando as condições adequadas, através do uso de signos e instrumentos, para que o aluno possa alcançar seu próximo nível de desenvolvimento. "Assim, para Vygotsky, o mecanismo de mudança individual ao longo do desenvolvimento tem sua raiz na sociedade e na cultura" (VYGOTSKY, apud COLE; SCRIBNER, 1991, p.11). A teoria do desenvolvimento em Vygotsky busca o registro das mudanças qualitativas que ocorrem ao longo do desenvolvimento do ser humano e não apenas o desenvolvimento da criança. A função da mediação é, pois a de otimizar esse processo de aprendizagem, partindo da competência do mediador em ensinar ou articular os recursos ambientais, materiais e cognitivos para modificação qualitativa das competências do indivíduo. Tébar (2011, p. 77) afirma que:

\begin{abstract}
A mediação é um fator humanizador de transmissão cultural. $O$ homem tem como fonte de mudança a cultura e os meios de informação. O mediador se interpõe entre os estímulos ou a informação exterior para interpretá-los e avaliá-los. Assim, o estímulo muda de significado, adquire um valor concreto e cria no indivíduo atitudes e críticas flexíveis. A explicação do mediador amplia o campo de compreensão de um dado ou de uma experiência, gera disposições novas no organismo e produz uma constante retroalimentação informativa (feedback). Trata-se de iluminar a partir de diferentes pontos um mesmo objeto do nosso olhar.
\end{abstract}

Para Feuerstein, existem duas modalidades de aprendizagem: a abordagem direta e a abordagem mediada. "A abordagem direta é expressa pela formula S-O-R de Piaget quando o aprendiz $(\mathrm{O})$ interage diretamente como estímulo (S) e dá resposta (R) a essa interação" (MENTIS, 2011, p.18). Na abordagem mediada, o ser humano (H) medeia a relação do aprendiz (O) com o objeto, e a fórmula proposta por Feuerstein é S-H-O-H-R, em que o aprendiz (O) tem sua relação com o estímulo (S) organizada e planejada pelo humano $(H)$ mediador, e a resposta $(R)$ dada pelo 


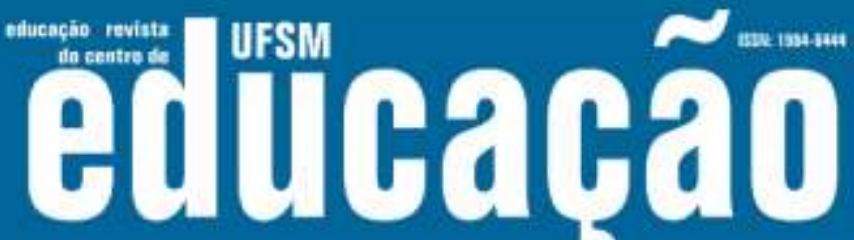

ISSN: 1984-6444 | http://dx.doi.org/10.5902/1984644434189

aprendiz é fruto da dinâmica desta interação social. O professor é o mediador entre os conhecimentos que o aluno possui e aqueles que se pretende que ele adquira.

\section{Professor Mediador}

O que distingue a atuação do professor das demais experiências mediadas presentes no cotidiano do aluno é a maneira planejada, intencional com que ele organiza a sua prática didática, considerando-se que: "os mediadores são todas as pessoas que organizam com intencionalidade sua interação e atribuem significados aos estímulos que o educando recebe" (TÉBAR, 2011, p. 114). O professor ajuda a suscitar o interesse e captar a atenção do aluno, trazendo-o para junto do objeto, a fim de que ao aprendê-lo derive benefícios desta experiência. Esse autor diz que a mediação flui no bojo da expressividade do professor, dirigida por sua competência didática. É o professor quem com intencionalidade, cultura e sensibilidade, filtra, seleciona e interpreta os estímulos da maneira mais apropriada, escolhendo o momento, a ordem, a intensidade e a forma mais adequada para apresentá-los.

A mediação demanda domínio da prática das relações humanas, porque, o mediador é um educador que assume completamente a responsabilidade de seu trabalho educativo, envolve-se na formação integral dos educandos dentro dos limites éticos e é cônscio de que o processo formativo é holístico, pois envolve todo o ser humano. Em suma, "o professor deve ter atitudes de empatia e acolhimento, de permanente interação, de críticas positivas da cultura e vivência dos valores que pretende transmitir" (TÉBAR, 2011, p.115).

O desempenho da função mediadora presume a intencionalidade de fazer a ponte no processo de aprendizagem. A função do suporte necessário fornecido pelo professor deve conduzir o aluno ao exercício de sua autonomia. Para cumprir esta função, o professor deve ter o necessário conhecimento do conjunto de saberes que envolvem as epistemologias que fundamentam o ato de aprender, além de habilidades e competências sobre mediação pedagógica no processo de ensinar, possibilitando ao estudante que aquilo que ele faz hoje com a ajuda do professor, possa fazer amanhã, sozinho (PIMENTEL, 2012). 


\title{
Autuaŗão
}

ISSN: 1984-6444 | http://dx.doi.org/10.5902/1984644434189

No processo de construção dos conhecimentos do próprio aluno, o professor é o mediador que gerencia, planeja e executa a aplicação das atividades e as relações dos sujeitos com o objeto a fim de atingir os objetivos de aprendizagem dos alunos. $O$ objetivo é a autonomia do aluno, pois ao estruturar sua ação, o professor tem em mente, "[...] de acordo com os princípios da aprendizagem significativa e construtivista, que os educandos são os protagonistas de sua própria aprendizagem" (TÉBAR, 2011, p.125). A autonomia do aluno é construída ao longo do trabalho docente quando este oferece oportunidades ao aluno de tomar decisões (FREIRE, 2006, p.120).

O professor medeia o processo de aprendizagem do aluno em direção à autonomia da aprendizagem, quando o aluno aprende a aprender. De acordo com os pressupostos da teoria do sócio construtivismo ou sócio-interacionismo de Vygotsky, a aprendizagem é construída no processo de interação social onde o conhecimento é mediado. A prática mediadora é ampla e se manifesta nas relações sociais. Não é somente o professor que cumpre o papel de mediador na vida do aluno, mas a família e a comunidade também o fazem, pois "[...]a mediação é uma forma de interação que engloba todos os âmbitos da vida dos educandos" (TÉBAR, 2011, p. 114).

A atuação intencional do professor permite que o aluno transcenda e perceba novos sentidos acrescentados pelo conhecimento adquirido, e desta forma desempenha o papel de mediador do processo de ensino-aprendizagem. A tecnologia e o uso da internet com finalidade educativa têm ampliado o espaço educacional para além da sala de aula, como observa Martins (2009, p. 18).

\begin{abstract}
Se estratégia, conteúdo, professor, aluno e intenções são ainda em nossos dias questões centrais da Didática, presente na sala de aula, é importante pensarmos sobre o que mudou nesse espaço escolar ao longo desses anos. Percebemos o quanto ele carece de um novo entendimento, de reflexões críticas sobre cada um desses componentes e sobre as interações que estabelecem entre si.
\end{abstract}

Compreendendo sua função no processo de ensino e aprendizagem, é relevante identificar os diversos parâmetros que perpassam a didática dos professores no seu papel de mediador. 


\section{U Us:

ISSN: 1984-6444 | http://dx.doi.org/10.5902/1984644434189

\section{Perfil do professor mediador segundo Reuven Feuerstein}

Neste item iremos abordar a proposta de Feuerstein, conforme o livro "Além da inteligência" de Feuerstein, Feuerstein e Falik (2014). A Experiência da Aprendizagem Mediada consiste em um sistema de crenças, teoria e parâmetros elaborados por Reuven Feuerstein cuja proposta é revolucionária. O axioma básico de sua teoria é que "as pessoas são modificáveis". No prefácio da obra supracitada, John Bransford relata que o próprio Feuerstein afirmava que foram duas as experiências que ele viveu e que determinaram o caminho que sua pesquisa tomou: a oportunidade de trabalhar com grandes mestres da educação e de ajudar crianças sobreviventes da Segunda Guerra Mundial que imigravam de todo o mundo para Israel.

Com o subsídio científico e a confiança na capacidade do ser humano de aprender, ele defende a plasticidade cognitiva e propõe que o professor intervenha nas formas de pensamento, no raciocínio lógico, nos instrumentos cognitivos dos alunos a fim de que estes alcancem a autonomia na aprendizagem através da mediação pedagógica. Aprendam a aprender.

No Brasil, convencionou-se chamar de "características" ou de "critérios da mediação" ao que Feuerstein denominou "parâmetros da mediação" (p.82). Neste artigo usamos os três termos indistintamente. De acordo com Feuerstein, a mediação possui diversos critérios ou características para ser desenvolvida, e os divide em dois grupos: os universais e os situacionais. Os universais são inerentes à capacidade humana de sua modificabilidade, e os situacionais estão relacionados à interação do indivíduo com o seu meio cultural e suas vivências.

Os parâmetros universais estão presentes em todas as culturas e são fundamentais para que ocorra a mediação. Eles são três: 1) Intencionalidade e reciprocidade; 2) Transcendência e 3) Significado. Os parâmetros situacionais se apresentam alternadamente nas relações de mediação, sendo eles: 4) Competência; 5) Regulação e controle de comportamento; 6) Comportamento de compartilhar; 7) Individualização e diferenciação psicológica; 8) Busca, colocação e alcance de objetivos; 9) Busca por desafio, novidade e complexidade; 10) Consciência de ser uma entidade modificável; 11) Alternativa otimista e 12) Sentimento de pertença. 


\section{T Lism

\section{Intencionalidade e Reciprocidade}

ISSN: 1984-6444 | http://dx.doi.org/10.5902/1984644434189

Nesses critérios, professor e aluno participam do processo, numa construção coletiva da aprendizagem de cada um. O mediador com intencionalidade planeja e realiza interações que geram reação recíproca favorável à aprendizagem. Ao se envolver neste processo de planejamento, o mediador irá lidar com indivíduos e recursos a fim de favorecer a aprendizagem, o material sendo aprendido, os componentes de tempo, lugar, ordem e organização atendidos (p.83).

$\mathrm{Na}$ intencionalidade do mediador os estímulos são moldados, pois ele faz com que sejam mais salientes, poderosos, compreensíveis e importantes para o receptor da mediação. O mediador também altera o receptor da mediação, ou seja, se o mediado está sonolento, o mediador induzirá um estado de alerta. Se o aluno responde lentamente, o mediador ajustará a taxa do fluxo de estímulo para o tempo do mediado para que possa ser absorvido.

No processo de ensinar e aprender ocorrem interações que mudam os envolvidos. Cada aluno ou experiência didática amplia os horizontes do docente e adicionam novos conhecimentos. Ao planejar o ensino e atuar junto ao aluno, o professor também desencadeia mudanças no aluno através do conhecimento, criando uma parceria, um pacto de aprendizagem que se estabelece entre ambos, pois a realização da docência se dá em um vir-a-ser constante.

\section{Transcendência}

Para responder à pergunta de como criamos a habilidade de transferir o que é aprendido a todas as áreas da vida, Feuerstein diz que esta é criada por meio da mediação da transcendência. Assim, "há um significado especial da transcendência, e é fator de humanização da interação entre o ser humano e o mundo." (p.87). Na realidade, os conhecimentos são criados a partir da transcendência, considerando-se que "a necessidade de sair e ir além da situação imediata de sobrevivência cria expressões e técnicas operacionais que se transmite para gerações futuras e garantem sua continuidade" (p.88).

$\mathrm{Na}$ transcendência, o professor orienta o aluno a planejar condutas, aplicando e generalizando aprendizagens, indo além da experiência direta e imediata, pois "na 


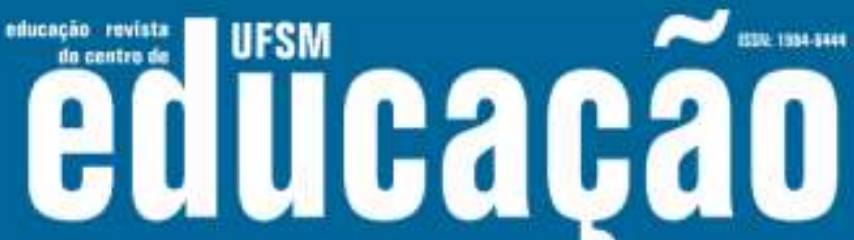

ISSN: 1984-6444 | http://dx.doi.org/10.5902/1984644434189

natureza existe um movimento essencial que requer mediação para objetivos que vão além da experiência direta e imediata" e ainda "a habilidade de agir em crescentes espaços de tempo, espaços e níveis de abstração é uma característica principal do desenvolvimento humano." (p.86). Quanto mais o professor oferecer oportunidade ao aluno de aplicar o conhecimento adquirido, mais possibilita o uso de criatividade ao executar tarefas e desenvolver a própria capacidade de aprender.

\section{Significado}

O professor, no ambiente da sala de aula, em outros lugares e no espaço virtual, deve oferecer ao aluno canais onde ele possa aplicar o conteúdo na sua vida. Na mediação de significado, o aluno busca e constrói sentido para sua vida e ações, associando e conectando novas situações aos significados positivos que foram dados às situações anteriores.

A característica ou parâmetro significado "é o que cria as forças motivacionais e emocionais que impulsionam nossa atividade e comportamento" (p. 89), o qual corresponde à definição de sentido para Vygotsky: é pessoal. O professor orienta e estimula o aluno na busca e construção de significados. A propensão mediada do indivíduo por buscar e construir significado para sua vida é o fator e força dirigente das transformações e desafios que serão realizados, porque "transições e mudanças durante a vida requerem que a pessoa adapte as novas situações aos significados que foram dados às situações anteriores na vida" (p. 91).

\section{Competência}

A mediação do sentimento de capacidade de agir eficazmente em um determinado tipo de situação, é necessária para que o ser humano se lance a enfrentar situações que demandem sua atuação. A participação do mediador no desenvolvimento do sentimento de competência, se dá a partir da retroalimentação da prática do aluno com o compartilhamento do parecer sobre suas ações.

Para tanto, um bom planejamento requer que o professor conheça os alunos. A medida certa de complexidade da tarefa é fator de estímulo ao sentimento de 


\section{Autuaŗão}

ISSN: 1984-6444 | http://dx.doi.org/10.5902/1984644434189

competência do aluno, por isso, ao planejar as atividades, o professor deve ter bom senso para designar tarefas que estão situadas a determinada distância do alcance imediato e, portanto, exigem maior esforço. O mediador fornece ao mediado ferramentas para lidar com novas tarefas, explicando com a ajuda da mediação o funcionamento bem sucedido do processo (p. 95).

A postura do mediador é de um personal trainer do desenvolvimento do aluno, pois pressupõe a designação de tarefas com nível adequado de dificuldade, o fornecimento de ferramentas que serão demandadas na execução da tarefa, a explicação do processo e o incentivo ao desempenho do aluno. Se o professor causar danos ao fluxo do processo ensino-aprendizagem, pode gerar insucessos no desempenho dos alunos que, na verdade, deveriam ser creditados a ele. Experiências de fracasso criam no aluno uma impermeabilidade que o impede de perceber as ações bem sucedidas que executam. De maneira concreta, o professor deve fornecer ao aluno feedback sobre seu desempenho, descrevendo objetivamente as ações que o levaram a ser bem sucedido. A observação pontual dos acertos dos alunos os leva a construir o sentimento de competência.

\section{Autorregulação}

A autorregulação é o exercício do autodomínio, ou seja, o professor mediador orienta e incentiva o aluno a desenvolver uma atitude reflexiva onde cada resposta demanda pesquisa, avaliação, reflexão a fim de otimizar a ação resultante. O exercício da autorregulação e do controle do comportamento demandam tempo para que o aluno trabalhe cognitivamente com as informações antes de responder ativamente a elas, porém:

em tais situações, professores podem interpretar a demora da resposta como evidência de falta de domínio do material estudado. Aqui, a mediação da regulação e controle de comportamento requer que o mediado considere os comportamentos e respostas potenciais, pense sobre eles, analise-os, e finalmente faça generalizações a partir deles (p. 98).

O professor precisa estar ciente que uma resposta ponderada necessita de tempo para ser construída e, portanto, o aluno precisa ter este tempo. A rapidez na resposta não necessariamente implica a qualidade, se não é uma situação de 


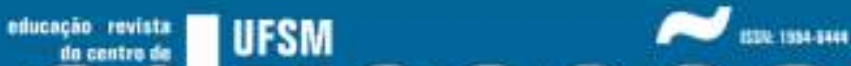

ISSN: 1984-6444 | http://dx.doi.org/10.5902/1984644434189

emergência, o professor deve conceder ao aluno o tempo necessário para pensar e consolidar sua resposta, antes de expressá-la.

\section{Compartilhamento}

O professor deve propiciar ao aluno, nos ambientes que dispõe, a mediação da habilidade de compartilhar as próprias experiências com o outro e permitir-se participar das experiências por ele vividas. Esse relacionamento saudável entre as pessoas permite a interação, pois, "a habilidade de compartilhar experiências com outros seres humanos e participar de suas experiências é necessário e desejável" ( $p$. 98). Compartilhar experiências intensifica o processo de aprendizagem ao permitir que tenhamos a oportunidade de nos ouvir, enquanto falamos para o outro e a interação que o diálogo proporciona permite

fazer alguém além de si mesmo participar de uma experiência emocional[...]O receptor do que compartilho participa no que é significativo para mim, confirmando minha experiência, e eu me ouço transmitindo minha experiência para outros, reforçando o significado e integridade da minha experiência (p.100).

O autor nos mostra que o processo de ensino aprendizagem é social e faz parte do papel do professor a criação de um ambiente acadêmico que favoreça a oportunidade de compartilhar experiências e o desenvolvimento de aptidões sociais. Além de falar, o professor precisa ouvir e criar condições e canais para que os alunos dialoguem em torno do tema da aula.

\section{Individuação}

O professor pode contribuir na mediação da conscientização da existência do aluno como uma entidade única, especial e separada, interagindo com outros de igual valor. O processo de mediação da individuação permite "[...] construir no ser humano um sentimento de individualização, de ser uma entidade separada, com o direito de pensar e expressar-se de uma forma especial que o distingue dos outros" (p.100). Tanto no discurso como na prática, o professor pode incentivar a unicidade de cada aluno respeitando as peculiaridades individuais e valorizando-as na produção do aluno, incentivando-o a ser sujeito e autor de suas ações e obras e não simples 


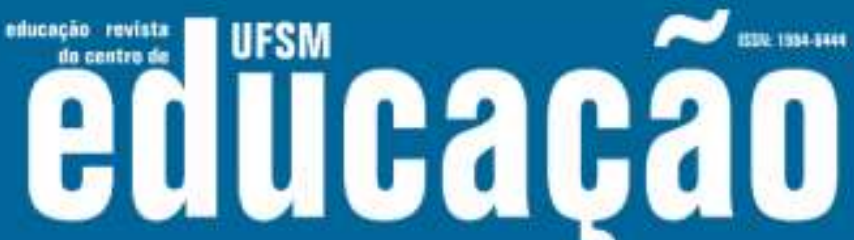

ISSN: 1984-6444 | http://dx.doi.org/10.5902/1984644434189

copiador do trabalho de outros. Todavia, o ser humano vive esta situação complexa de ser um indivíduo que se realiza e se constrói na interação social. Portanto, ao reconhecer sua individualidade, o ser humano tem condições de interagir, estar inteiro para poder doar-se sem perder o referencial de si mesmo.

\section{Objetivos}

Por meio da mediação dos objetivos, estratégias são criadas e o levantamento de informações de qualidade, precisas e rigorosas, é feito para que se permitam atingilos. Ocorre a reflexão sobre situações que ainda não são reais, o exercício do planejamento, pois:

a presença de um objetivo no repertório mental de um indivíduo reflete o início de uma modalidade representacional (abstrata) de pensamento. O mediador apresenta para o mediado uma variedade de potenciais objetivos, muitos dos quais aumentam a esfera de consciência do mediado com relação ao que é possível, desejável e alcançável (p.102)

"[...] a colocação de objetivos distantes e investimentos em planos e ações para alcançá-los, apesar do fato de serem alcançados apenas no futuro, é o que cria valor transcendental, a ampliação do campo mental e senso de tempo e espaço expandido (p. 103)."

Para tanto, o professor deve propor ao aluno oportunidade de trabalhar com situações-problema ou na execução de projetos que o levem a lidar com dados de tempo e espaço que ainda não estão em sua vivência. É dessa maneira que o professor faz a mediação dos objetivos e o aluno aprende, a partir de dados e análise de situações presentes a projetar ações e situações futuras.

\section{Desafio}

A mediação do comportamento desafiador faz suscitar curiosidade, aceitação e, às vezes, expandir as vivencias do aprendiz, visto que objetiva aumentar a adaptabilidade do indivíduo para as mudanças e complexidades do mundo. O exercício da habilidade de enfrentar e vencer desafios ativa a "curiosidade, aceitação e eventual expansão do repertório de experiências do aprendiz" (p.105). No mundo dinâmico da Era da Informação, o enfrentamento de novos desafios compõe o repertório de nossas experiências diárias e ser munido de habilidade para enfrentá- 


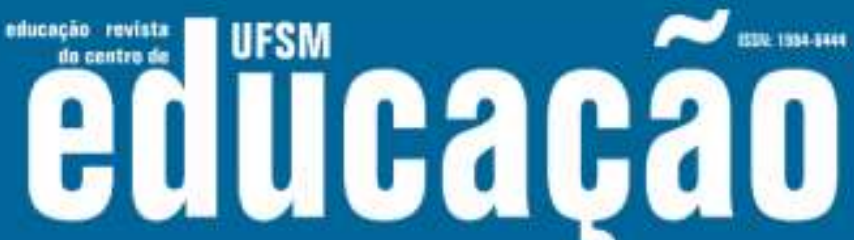

ISSN: 1984-6444 | http://dx.doi.org/10.5902/1984644434189

los aumenta a probabilidade de que eles se tornem experiências positivas de aprendizagem que venham a enriquecer nossa história pessoal.

\section{Automodificação}

O mediador contribui com a construção no aluno da autoconsciência de saber se modificar, a expectativa positiva e ciência de que é possível aprender. Se sob um ponto de vista determinista o professor desconsiderasse 0 potencial de modificabilidade cognitiva do aluno, sua interferência se tornaria desnecessária, pois a aprendizagem fluiria sem esforço para os antecipadamente preparados. Por outro lado, os alunos que dependem de mediação para aprender a lidar com a cultura acadêmica, estariam simplesmente fadados ao fracasso escolar, uma vez que as potencialidades não seriam alcançadas e as dificuldades não seriam superadas.

Como a inação não gera modificabilidade, a aprendizagem implica mudanças. Sendo assim, "o mediador deve, portanto, trabalhar ativamente para criar na pessoa o sentimento de ser modificável." (p.106). Nesse contexto, o processo avaliativo pode ser usado como importante ferramenta na mediação da automodificação, pois seu uso permite realizar um prognóstico mais dinâmico e otimista. A partir do conhecimento do ponto de domínio que o aluno detém, o professor verifica seu progresso, pondera seu ritmo de avanço e investe naquilo que melhor funciona, para isto o professor necessita da formação adequada para enfrentar os desafios profissionais.

\section{A formação do professor}

A escola é um espaço pleno de oportunidades para que a experiência de aprendizagem mediada (EAM) aconteça. Para o desenvolvimento da intencionalidade do processo de ensino e aprendizagem, cabe ao professor, tendo em vista o objetivo estabelecido e o conteúdo elencado, planejar e executar as atividades que gerarão estímulos ao estudante a fim de que ele interaja e se aproprie de novos conceitos, informações, experiências, que gerarão novos significados.

A definição das qualidades inerentes à profissão favorece a formação de docentes preparados para contribuir na formação dos cidadãos. A eficácia dos 


\section{=1 usm $\sim$

ISSN: 1984-6444 | http://dx.doi.org/10.5902/1984644434189

métodos, dos enfoques didáticos e as qualidades que os docentes devem possuir, precisam ser objetos de investigação a fim de que se possam ter elementos que melhor caracterizem o profissional deste campo. Este é um indicador apontado pela UNESCO (1998, p. 63) que continua presente:

É importante oferecer aos futuros professores uma formação nos métodos didáticos; no entanto[...] há poucas informações sistemáticas sobre a eficácia dos diversos métodos, ou enfoques didáticos em distintas matérias, em diferentes países ou sobre as qualidades que os docentes devem possuir para poder colocá-los em prática de modo satisfatório.

Apesar de Vygotsky não ter formulado uma teoria pedagógica, contribuiu, através do desenvolvimento de conceitos sobre o processo de ensino aprendizagem no sociointeracionismo e da Zona de Desenvolvimento Proximal, para sua formulação. No conceito de zona proximal, Vygotsky mostrou que o ensino eficiente é aquele que estimula a criança a atingir um nível de compreensão e habilidade que ainda não domina completamente, "puxando" dela um novo conhecimento. Adultos e crianças são aprendizes. E a atuação do professor de professores em formação também se passa nesta ZPD. A ênfase que Vygotsky dá ao aprendizado ressalta a importância da instituição escolar na formação do conhecimento, visto que a intervenção pedagógica provoca avanços que não ocorreriam espontaneamente. O que nos leva à condição do professor, o qual, com sua prática, contribui com a formação de novos professores, pois

ninguém começa a ser educador numa certa terça-feira às quatro horas da tarde. Ninguém nasce educador ou é marcado para ser educador. A gente se faz educador, a gente se forma como educador permanente na prática e na reflexão sobre a prática (FREIRE, 1991, p.58).

Este "fazer-se educador" e "formar-se educador" são baseados no exercício da profissão e na reflexão crítica que cada um faz de sua prática diante dos referenciais teórico-práticos aos quais ele acessa.

Feuerstein desenvolveu as teorias da Modificabilidade Cognitiva Estrutural (MCE) e EAM (Experiência de Aprendizagem Mediada) através do Processo de Aprendizagem Enriquecimento Instrumental (PEI), as quais fornecerão os indicadores do perfil do professor bem sucedido no processo de mediação da aprendizagem de acordo com Feuerstein, de modo que contribua com a "[...] concepção de formação 


\section{usm

ISSN: 1984-6444 | http://dx.doi.org/10.5902/1984644434189

docente compatível com o perfil das instituições de EPT" (MOURA, 2008) a fim de favorecer o desenvolvimento humano e a coesão social (KASSAR, 2011).

A respeito da Teoria da Modificabilidade Cognitiva Estrutural (MCE) ou teoria da mediação da aprendizagem, Meier e Rolim (2014, p.1) afirmam que

a neurociência vem comprovando muitas afirmações da teoria da mediação evidenciando que o fator mais importante para o desenvolvimento da inteligência de uma pessoa, seja ela criança ou adulta, é a qualidade da interação que recebe de alguém que conhece mais que ela. É o resgate do valor do professor.

O papel do professor é complexo, porque vai muito além da simples tarefa de expor conhecimentos:

Desenvolver pessoas não é apenas dar-lhes informação para que elas aprendam novos conhecimentos, habilidades e destrezas e se tornem mais eficientes naquilo que fazem. É, sobretudo, dar-lhes a formação básica para que elas aprendam novas atitudes, soluções, ideias, conceitos e que modifiquem seus hábitos e comportamentos e se tornem mais eficazes naquilo que fazem. Formar é muito mais do que simplesmente informar, pois representa um enriquecimento da personalidade humana (CHIAVENATO, 2010, p.362).

A ação do professor como mediador é extremamente importante já que sua práxis se traduz em veículo de transformação social. A identificação das competências didáticas que favorecem o desempenho de seu papel no processo ensino/aprendizagem pode disponibilizar ferramentas adequadas para o exercício de sua função. A pertinência destas questões para o conhecimento do objeto de estudo, remontam à Grécia Antiga (HEIDEGGER, 2012, p. 13) e estão presentes na doutrina aristotélica das quatro causas: "materialis, formalis, finalis e efficiens", mas, precisam ir além, pois a mediação é o processo interativo onde ensino e aprendizagem ocorrem. É a didática em exercício.

\section{Aspectos metodológicos}

A abordagem utilizada nesta pesquisa foi a pesquisa bibliográfica e descritiva, considerando que nos propomos a descrever a construção de um instrumento de avaliação, tendo como público-alvo o professor de qualquer nível ou modalidade de ensino. A construção do instrumento seguiu os procedimentos de Pasquali (1998). 


\section{usm eillbapaO

\section{Objetivo Geral}

ISSN: 1984-6444 | http://dx.doi.org/10.5902/1984644434189

Construir uma ferramenta que auxilie na identificação do perfil do professor mediador na sua prática docente.

\section{Objetivos Específicos}

a) Identificar as principais características didáticas pertinentes ao perfil do professor mediador;

b) Elaborar um instrumento que possa contribuir com a autoavaliação docente tendo em vista os indicadores do perfil do professor mediador;

\section{Procedimento}

Os primeiros passos deste trabalho foram dados, por meio da pesquisa bibliográfica que visou caracterizar o perfil do professor mediador a partir das teorias que fundamentam a pedagogia da mediação e o mapeamento das características pertinentes a este perfil em qualquer nível ou modalidade de ensino. A construção do instrumento teve como base os parâmetros didáticos do professor mediador identificados e caracterizados na literatura disponível. Posteriormente, foram operacionalizadas as variáveis para a construção do instrumento. Também fez parte da fase qualitativa a avaliação da proposta através do parecer e das sugestões dos juízes, bem como o pré-teste, os quais serão abordados no próximo item.

\section{Construção do instrumento}

O Questionário sobre o Perfil Didático do Mediador foi desenvolvido por Lorenzo Tébar em sua tese de doutorado, em ciências da educação na Espanha (TÉBAR, 2011, p. 134 e 135). Neste trabalho, o autor elabora uma escala de 32 itens relacionados às características didáticas do professor mediador a partir do Programa de Enriquecimento Instrumental (PEI).

O instrumento desenvolvido por Feuerstein, Avaliação do Professor Mediador, é um documento do Instituto para a pesquisa Hadassah Wizo-Canadá e das Oficinas Internacionais Shoresh, Israel (TÉBAR, 2011, p. 509-511). Centra-se na avaliação 


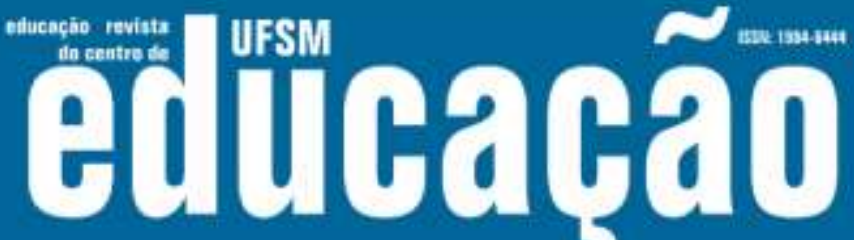

ISSN: 1984-6444 | http://dx.doi.org/10.5902/1984644434189

qualitativa de uma lição do Programa de Enriquecimento Instrumental desenvolvido por Reuven Feuerstein e é composto por três formulários: (1) Formulário de Avaliação; (2) Questionário de Avaliação do Professor; e (3) Contribuições Pessoais quanto à Experiência com o Programa de Enriquecimento Instrumental (PEI). É ministrado de acordo com os princípios da Experiência de Aprendizagem Mediada e da teoria da Modificabilidade Cognitiva.

A Avaliação do professor mediador é composta por doze itens cujo objetivo é avaliar aspectos do tema de sua aula e a qualidade de sua apresentação em uma escala de 1 a 5 (sendo 1 a pontuação mais baixa e 5 a mais alta). No Questionário de Avaliação do Professor, o ponto de vista é do observador da aula, o qual avalia as ações do professor e do aluno, registrando pontuação de 1 a 5 (sendo 1 a pontuação mais baixa, e 5 a mais alta) e quaisquer observações pertinentes aos dezessete tópicos. Nas Contribuições Pessoais, quanto à experiência com o programa de enriquecimento instrumental (PEI), o professor responde a nove questionamentos sobre sua experiência com o $\mathrm{PEI}$, podendo anexar registros de sua autoria referente ao tema, uma vez que o ponto de vista é do observador da aula.

A pesquisa suscitou a necessidade de se construir um questionário que focasse a prática docente, a partir do construto das dez características do professor mediador, introduzidas por Feuerstein, em seu livro "Além da Inteligência" que ressaltava a aplicabilidade dos princípios do PEI, EAM e MCE que permeiam a prática docente com significativos resultados positivos no ensino aprendizagem.

Foi realizado também o levantamento da nomenclatura em cinco obras de autores que tratam da temática, os quais são: Feuerstein, Feuerstein e Falik (2014); Tébar (2011); Mentis et al (2011); Souza, Depresbiteris e Machado (2003); Ros (2002). Nesta pesquisa e no questionário, adotou-se a mesma sequência de exposição dos parâmetros definidos por Feuerstein, Feuerstein e Falik (2014, p. 83102) e seguiu-se também a opção dos demais autores ao trabalhar apenas com os dez primeiros parâmetros. Quanto à nomenclatura, procurou-se selecionar a mais sucinta a fim de facilitar o uso dos termos e a identificação de cada um.

A escolha para os quatro primeiros parâmetros são, de acordo com Feuerstein: Intencionalidade e Reciprocidade, Transcendência, Significado e, Competência. Para 


\section{Autuaŗão}

ISSN: 1984-6444 | http://dx.doi.org/10.5902/1984644434189

o parâmetro 5, optou-se pela denominação de Ros (2002): Autorregulação. Os parâmetros 6, 9 e 10 foram designados de acordo com Mentis et al (2011) e Souza, Depresbiteris e Machado (2003): Compartilhamento, Desafio e Automodificação. No parâmetro 7, optou-se pelo neologismo Individuação, usado por Mentis et al, por considerarmos que o termo encerra em si as ideias de individualização e diferenciação psicológica. No parâmetro 8, optou-se pela palavra Objetivos, diferentemente dos autores pesquisados, sem explicitar no título os termos busca, colocação e alcance. Os motivos foram: manter a objetividade na nomenclatura dos parâmetros, seguindo o padrão de utilização de apenas um substantivo, com exceção do primeiro parâmetro, no qual se justifica a utilização dos dois termos pela ausência de um único termo que encerre seu sentido. Os parâmetros adotados neste trabalho são: 1. Intencionalidade e reciprocidade; 2. Transcendência; 3. Significado; 4. Competência; 5. Autorregulação; 6. Compartilhamento; 7. Individuação; 8. Objetivos; 9. Desafio e 10. Automodificação.

O modelo proposto por Pasquali (1998) se baseia em três grandes polos ou procedimentos: teóricos, empíricos ou experimentais e analíticos ou estatísticos. Neste estudo apresentaremos os procedimentos teóricos do construto mediação para o qual o instrumento de medida seria construído, que são as dez características do professor mediador de acordo com Reuven Feuerstein. A partir do levantamento das características de mediação, procedeu-se à operacionalização do construto seguindo as regras de construção dos itens de Pasquali.

A partir da identificação das dez principais características de mediação em Feuerstein, fundamentou-se a caracterização de cada uma delas, identificando-se os comportamentos operativos que delas derivam. Ficou estabelecido que cada parâmetro teria três variáveis, totalizando trinta itens, apresentados na Escala Likert de cinco pontos, observando as 12 regras elencadas por Pasquali (1998, p. 212-214). Dos trinta itens, oito foram construídos com a finalidade de que a valorização ocorresse de maneira inversa. O objetivo foi evitar um raciocínio linear que levasse os respondentes a dar uma mesma resposta automaticamente, incentivando-os a ponderar sobre as afirmações e o valor atribuído a cada uma deles. Após essa fase a proposta foi submetida à avaliação de juízes e pré-teste. 


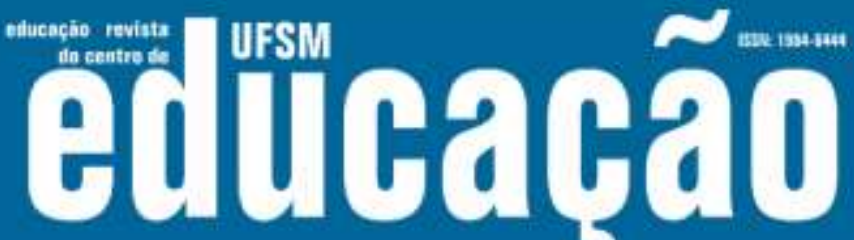

ISSN: 1984-6444 | http://dx.doi.org/10.5902/1984644434189

$\mathrm{Na}$ construção dos itens, optou-se pela utilização da escala intervalar, na qual o respondente mede seu nível de concordância com a atitude descrita na sentença sobre uma série contínua que vai de altamente favorável até altamente desfavorável, ou vice-versa, com igual número de possibilidades positivas e negativas de resposta e uma categoria média ou neutra (REA; PARKER, 2000). Desta forma o grau de concordância variou da seguinte forma: 1 - Completamente em desacordo/Nunca ajo assim; 2 - Em desacordo/Poucas vezes ajo assim; 3 - Indiferente; 4 - De acordo/Costumo agir assim; 5 - Completamente de acordo/Sempre ajo assim. Os termos foram os mesmos utilizados por Tébar, com adaptações nos termos do valor 3 (TÉBAR, 2011, p. 134). As informações e orientações para o preenchimento do questionários são muito importantes, como alertam Guerreiro, Almeida e Silva Filho (2014).

O instrumento final consistiu em um questionário semiestruturado dividido em três partes: a primeira parte refere-se às competências do professor mediador e o grau de concordância do respondente às sentenças apresentadas; a segunda parte consistiu em duas perguntas abertas sobre a prática docente. Na terceira parte, fazse o levantamento dos dados gerais do participante da pesquisa. Porém, será apresentado apenas a primeira parte.

\section{Avaliação do instrumento}

Inicialmente o questionário foi constituído por 38 itens (provisórios). Esta proposta provisória passou por dois critérios de avaliação: julgamento e pré-teste. No julgamento, foi feita a análise psicométrica do instrumento. No pré-teste, o questionário foi respondido por um público que exerce a prática docente. Teceremos mais detalhes a seguir.

\section{O Julgamento do Instrumento}

O julgamento foi encaminhado para dez juízes especialistas em avaliação de escalas psicométricas ou linguísticas (doutores, mestres e alunos do mestrado em Psicologia). Apesar de oito aceitarem a tarefa, apenas cinco enviaram o questionário 


\section{Fus

ISSN: 1984-6444 | http://dx.doi.org/10.5902/1984644434189

com seu parecer. As tarefas que solicitamos aos mesmos foram:1) Analisar se os itens são pertinentes, em relação a cada critério que se pretende medir;2) Analisar semanticamente se o texto está acessível, compreensível e adequado para evocar respostas correspondentes. Disponibilizou-se ainda espaço para a apresentação de sugestões para melhoria de cada item. O contato com os juízes deu-se através de emails. O resultado do julgamento foi tabulado e as sugestões foram analisadas e acatadas, conforme a pertinência.

Os dados foram analisados estatisticamente no Excel, fazendo-se a avaliação da mediana e da moda dos itens da escala Likert. Esta medida é especialmente útil para reduzir a informação de um conjunto de dados qualitativos, apresentados sob a forma de nomes ou categorias, para os quais não se pode calcular a média e por vezes a mediana. Os itens que alcançaram média 3 ou menor que três, tanto no cálculo da Moda quanto da Mediana, foram reestruturados ou excluídos. Contudo, mesmo os itens que alcançaram índices superior ou igual a quatro, e sobre os quais os juízes emitiram parecer, suas sugestões foram consideradas e avaliadas.

\section{Pré-Teste}

O pré-teste foi aplicado pessoalmente a dez alunos de um mestrado profissional, os quais também são professores que atuam na área da educação como pedagogos, professores da Educação Básica e Superior. A escolha dos respondentes foi aleatória. O objetivo era avaliar a acessibilidade, compreensão e adequação do texto para evocar respostas correspondentes. O resultado do pré-teste foi tabulado e avaliado estatisticamente a fim de se verificar a frequência das respostas.

\section{Proposta de Produto Final}

O título adotado para a apresentação do produto gerado pela pesquisa foi "Questionário ProfMed: perfil do professor mediador" (Figura 1). O público-alvo original foram os professores de uma instituição de ensino tecnológico, em virtude da dissertação de mestrado da autora. Mas, o mesmo pode ser aplicado a professores em outros contextos acadêmicos. Sua proposta e aplicação serão apresentadas a seguir. 


\section{Ailloapẫ}

ISSN: 1984-6444 | http://dx.doi.org/10.5902/1984644434189

A pontuação atribuída é a mesma para cada item, independentemente do modo ou propósito de aplicação. O valor de cada assertiva varia de 1 a 5 pontos conforme a alternativa de valor registrada. Se o grau de concordância for 4 , o valor a ser registrado será 4. Contudo, quando a questão é invertida, a pontuação é inversamente proporcional, exceto o valor 3 (neutro). As questões invertidas estão nos itens 2, 5, 6, $9,17,21,22$ e 27.

O Quadro 1 apresenta uma proposta de pontuação, que é um registro de avaliação individual, com um exemplo hipotético. Na primeira linha, temos os níveis de mediação e, na primeira coluna, as características didáticas do professor mediador. Se o objetivo for a identificação do nível de mediação por característica, deve-se somar por linha, fazendo o registro da pontuação obtida, entre 3 e 15. Caso queira considerar o nível de mediação total, basta somar os pontos alcançados nas colunas, o resultado será entre 30 e 150.

Salientamos que o Questionário ProfMed se limita a mensurar o nível de mediação didática com base nas respostas dadas pelo professor e que esta mensuração não tem a intenção de assumir um caráter de teste, onde alguém seria aprovado ou reprovado, mas um instrumento de reflexão da prática didática com indicativos de áreas a serem trabalhadas através da formação contínua. 


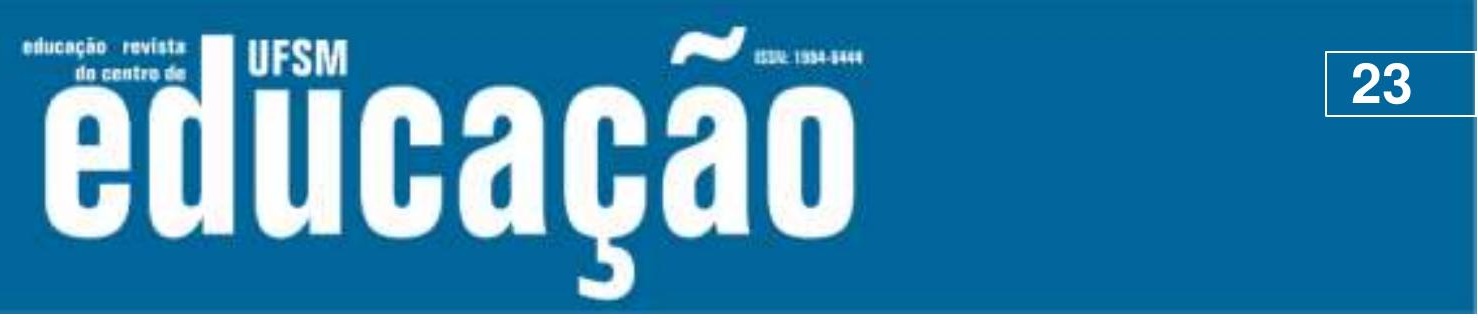

ISSN: 1984-6444 | http://dx.doi.org/10.5902/1984644434189

Figura 1 - Questionário ProfMed.

\section{Questionário ProfMed

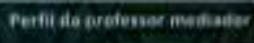

Código de Identificaçăo:

I. PERFIL DIDÁTICO

Leis atentamente a escala abaixo e, em seguida, circule a numeraçlo que expresse o grau de concordancio ou discordancia em relaça aos itens apresentados. Por favor, nåo dexe nenhum item em branco.

\begin{tabular}{|c|c|c|c|c|c|c|}
\hline \multicolumn{7}{|c|}{$\begin{array}{l}\text { ESCALA - Intensidade de confirmaço ou ndo a frase exposta. } \\
\text { 1. Completamente em desacordo. Nunca ajo assim. } \\
\text { 2. Em desacordo. Raramente ajo assim. } \\
\text { 3. Indiferente. As vezes ajo assim. } \\
\text { 4. De acordo. Multas vezes ajo assim. } \\
\text { 5. Completamente de acorda. Sempre ajo assim. }\end{array}$} \\
\hline 1. & Diversifico os recursos utilizados para o ensino dos alunos. & 1 & 2 & 3 & 4 & 5 \\
\hline 2. & $\begin{array}{l}\text { Acredito que os valores, costumes e normas que regulam e moldam os comportamen- } \\
\text { tos slo adquiridos apenas fore da sala de aula. }\end{array}$ & 1 & 2 & 3 & 4 & 5 \\
\hline 3. & $\begin{array}{l}\text { Auxilio os alunos para que descubram que o conhecimento adquirido em minha disch- } \\
\text { plina pode ser util no seu dia-a-dia. }\end{array}$ & 1 & 2 & 3 & 4 & 5 \\
\hline 4. & $\begin{array}{l}\text { Ao observar um aluno desempenhando uma attvidade com competencia procuro tor- } \\
\text { na-lo consciente de seu sucesso. }\end{array}$ & 1 & 2 & 3 & 4 & 5 \\
\hline 5. & Solicito açes cujo resultado seja imediato. & 1 & 2 & 3 & 4 & 5 \\
\hline 6. & Procuro nâo envolver os alunos em atividades de grupo para evitar conflitos. & 1 & 2 & 3 & 4 & 5 \\
\hline 7. & Estimulo os alunos a terem sua própria forma de pensar. & 1 & 2. & 3 & 4 & 5 \\
\hline 8. & Estimulo meus alunos a planejarem seus objetivos. & 1 & 2 & 3 & 4 & 5 \\
\hline 9. & Nem sempre ofereço novidades e desafios no processo de ensino. & 1 & 2 & 3 & 4 & 5 \\
\hline 10. & Acredito na capacidade de automodificaça do aluno. & 1 & 2 & 3 & 4 & 5 \\
\hline 11. & $\begin{array}{l}\text { Busco que os alunos apliquem o conhecimento adquiride em minha disciplina em ou- } \\
\text { tras materias curriculares. }\end{array}$ & 1 & 2 & 3 & 4 & 5 \\
\hline 12. & Torno o conteôdo compreensivel pare os alunos. & 1 & 2 & 3 & 4 & 5 \\
\hline 13. & Busco estimular meus alunos a pensarem alén do conteddo programatico. & 1 & 2 & 3 & 4 & 5 \\
\hline 14. & Forneso ferramentas que permitam ao aluno lider com novas tarefas. & 1 & 2 & 3 & 4 & 5 \\
\hline 15. & Oriento meus alunos para que pensem sobre as situacbes. & 1 & 2 & 3 & 4 & 5 \\
\hline 16. & $\begin{array}{l}\text { Permito que os alunos contribuam com o compartilhamento de experitencias que enri- } \\
\text { queçam o processo de aprendizagem. }\end{array}$ & 1 & 2 & 3 & 4 & 5 \\
\hline 17. & $\begin{array}{l}\text { Oriento os alunos a terem estilos e ativides que correspondam ao que considero como } \\
\text { correto. }\end{array}$ & 1 & 2 & 3 & 4 & 5 \\
\hline 18. & Trabalho a habilidade dos alunos de usar a imaginacalo. & 1 & 2 & 3 & 4 & 5 \\
\hline 19. & $\begin{array}{l}\text { Após cumprir um desaflo, proponho ao aluno novas atividades com nivel diferente de } \\
\text { complexidade. }\end{array}$ & 1 & 2 & 3 & 4 & 5 \\
\hline 20. & Acredito na possiblidade de superaçăo de alunos com dificuldade de aprendizagem. & 1 & 2 & 3 & 4 & 5 \\
\hline 21. & Considero o aluno como o ûnico responsável por sua própria aprendizagem. & 1 & 2 & 3 & 4 & 5 \\
\hline 22. & $\begin{array}{l}\text { Nho faz parte do meu papel de professor conhecer os alunos além das suas responsa- } \\
\text { bilidades academicas. }\end{array}$ & 1 & 2 & 3 & 4 & 5 \\
\hline 23. & $\begin{array}{l}\text { Procuro despertar nos alunos a necessidade de alcançar um nivel mais elevado de de- } \\
\text { senvolvimento humano. }\end{array}$ & 1 & 2 & 3 & 4 & 5 \\
\hline 24. & Atravts da mediaçlo com os alunos colaboro para que se sintam capazes. & 1 & 2 & 3 & 4 & 5 \\
\hline 25. & Trabalho com as alunos o planejamento de suas açbes. & 1 & 2 & 3 & 4 & 5 \\
\hline 26. & Acredito que compartithar experienclas é uma necessidade do ser humano. & 1 & 2 & 3 & 4 & 5 \\
\hline 27. & Aceito o jeito de ser de cada aluno. No entanto, alguns me incomodam. & 1 & 2 & 3 & 4 & 5 \\
\hline 28. & $\begin{array}{l}\text { Reconheço que a cada desaflo cumprido o aluno se torna apto a ir altem da area que } \\
\text { the e familiar. }\end{array}$ & 1 & 2 & 3 & 4 & 5 \\
\hline 29. & Conflo na capacidade dos alunos de se superarem na execuçalo de tarefas. & 1 & 2 & 3 & 4 & 5 \\
\hline 30. & Busco sinais de evoluçäo na aprendizagem dos alunos a cada avaliaça. & 1 & 2 & 3 & 4 & 5 \\
\hline
\end{tabular}

Fonte: As autoras. 


\section{تีtônẫ

ISSN: 1984-6444 | http://dx.doi.org/10.5902/1984644434189

Quadro 1- Escala de pontuação do ProfMed.

\begin{tabular}{|c|c|c|c|c|c|c|}
\hline \multirow{2}{*}{$\begin{array}{l}\text { Parâmetros de } \\
\text { mediação }\end{array}$} & Não há & Insuficiente & Regular & Boa & Ótima & \multirow{2}{*}{$\begin{array}{l}\text { Mediação por } \\
\text { parâmetro }\end{array}$} \\
\hline & $\geq 3$ & $4 \geq 6$ & $7 \geq 9$ & $10 \geq 12$ & $13 \geq 15$ & \\
\hline $\begin{array}{l}\text { Intencionalidade e } \\
\text { reciprocidade }\end{array}$ & & & & 10 & & Boa \\
\hline Transcendência & & 5 & & & & Insuficiente \\
\hline Significado & & & 8 & & & Regular \\
\hline Competência & & & & 10 & & Boa \\
\hline Autorregulação & 1 & & & & & Não há \\
\hline Compartilhamento & & 4 & & & & Insuficiente \\
\hline Individuação & & & 7 & & & Regular \\
\hline Objetivos & & & & & 13 & Ótimo \\
\hline Desafio & 2 & & & & & Não há \\
\hline Automodificação & 2 & & & & & Não há \\
\hline \multirow[t]{2}{*}{ Total parcial } & & & & & & Total geral \\
\hline & 5 & 9 & 15 & 20 & 13 & \multirow[t]{2}{*}{ Regular } \\
\hline \multirow[t]{2}{*}{ Mediação total } & Não há & Insuficiente & Regular & Boa & Ótima & \\
\hline & $\geq 30$ & $31 \geq 60$ & $61 \geq 90$ & $91 \geq 120$ & $121 \geq 150$ & 62 \\
\hline
\end{tabular}

Fonte: As autoras.

\section{Conclusão e considerações finais}

A partir do objetivo de construir uma ferramenta que auxilie na autoavaliação do professor por meio do perfil do professor mediador, concluímos que atingimos a meta. Sugerimos sua utilização como instrumento ativador de debates em reuniões de professores; como instrumento de avaliação diagnóstica em oficinas de pedagogia da mediação ou como instrumento de autoavaliação. Propomos ainda que o questionário, e a pesquisa exposta neste trabalho, sejam ferramentas utilizadas para contribuir com a prática dos docentes tendo em vista o quadro esboçado através dos indicadores apontados pela pesquisa.

O questionário limitou-se a avaliar como o professor se vê no desempenho de trabalho em sala de aula como professor mediador. Diversos aspectos foram colocados à margem desta pesquisa em função da objetividade da mesma. Por exemplo, não foi objetivo deste trabalho avaliar o perfil didático do professor mediador sob o ponto de vista de seus alunos, de seus coordenadores e pedagogos, ou sob o ponto de vista do pesquisador no ato de seu desempenho didático. Porém, certamente estas limitações podem se configurar como sugestões para futuras pesquisas. 


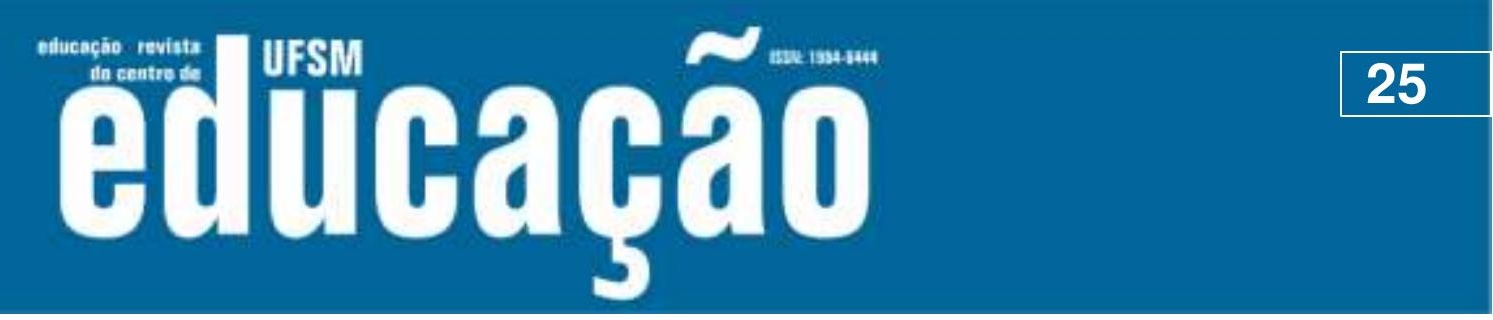

\section{Referências}

ISSN: 1984-6444 | http://dx.doi.org/10.5902/1984644434189

CHIAVENATO, I. Gestão de Pessoas: o novo papel de dos recursos humanos nas organizações. Rio de Janeiro: Elsevier, 2010.

CORREA, R. C. R. Uma proposta de reabilitação neuropsicológica através do programa de enriquecimento instrumental (PEI). Ciênc. cogn., Rio de Janeiro, v. 14, n. 2, p. 47-58, jul. 2009. Disponível em: <http://pepsic.bvsalud.org/scielo.php?script=sci_arttext \&pid=S1806-58212009000200005\&lng=pt\&nrm=iso>. Acesso em 28 jun. 2018.

DEMO, P. Habilidades do século XXI. Boletim Técnico do Senac, Rio de Janeiro, v. 34, n. 2, p. 4-15, 2008.

FEUERSTEIN, R.; FEUERSTEIN, R. S.; FALIK, L. H. Além da inteligência: aprendizagem mediada e a capacidade de mudança do cérebro. Petrópolis, RJ: Vozes, 2014.

FREIRE, P. A Educação na Cidade. São Paulo: Cortez, 1991.

FREIRE, P. Pedagogia da autonomia: saberes à prática educativa. São Paulo: Paz e Terra, 2006.

GUERREIRO, E. M. B. R.; ALMEIDA, M. A.; SILVA FILHO, J. H. Avaliação da satisfação do aluno com deficiência no ensino superior. Avaliação, Campinas; Sorocaba, SP, v. 19, n. 1, p. 31-60, mar. 2014. Disponível em: <http://www.scielo.br/pdf/aval/v19n1/03.pdf>.Acesso em 28 jun. 2018.

HEIDEGGER, M. Ensaios e Conferências. 8 ed. Petrópolis: Vozes: Bragança Paulista: Editora Universitária São Francisco, 2012.

KASSAR, M. C. M. Percursos da constituição de uma política brasileira de Educação Especial Inclusiva. Rev. Bras. Ed. Esp., Marília, v. 17, p. 41-58, maio-ago., 2011. Edição Especial. Disponível em: <http://www.scielo.br/pdf/rbee/v17nspe1/05.pdf>. Acesso em: 28 jun. 2018.

MARTINS, J. C.; PIMENTEL, L. S. L. O fazer pedagógico: (re)significando o olhar do educador. Rio de Janeiro: Wak Ed., 2009.

MEIER, M.; ROLIM, J. Reuven Feuerstein faleceu. MEIER \& ROLIM Educação e Treinamento. Disponível em: <http://marcosmeier.blogspot.com/2014/04/reuvenfeuerstein-faleceu.html>. Acesso em: 28 jun. de 2018.

MENTIS, M. Aprendizagem mediada dentro e fora da sala de aula. Programa de Pesquisa Cognitiva/Divisão de Educação Especializada da Universidade de Witwatersrand - África do Sul. Tradução José Francisco Azevedo. 4 ed. São Paulo: SENAC, 2011. 


\section{Tusm oitibarato}

ISSN: 1984-6444 | http://dx.doi.org/10.5902/1984644434189

MOITA, M. C. Percursos de formação e transformação. In: NÓVOA, A. (Org.) Vidas de professores. 2 ed. Porto: Porto Editora (Coleção Ciências da Educação), 1995.

MOURA, D. H. A formação de docentes para a educação profissional e tecnológica. Revista Brasileira da Educação Profissional e Tecnológica, v. 1, n. 1, jun. 2008. Brasília: MEC, SETEC, 2008. p. 23-38. Disponível em: <http://portal.mec.gov.br/setec/arquivos/pdf3/rev_brasileira.pdf>. Acesso em: 28 jun. 2018.

PASQUALI, L. Princípios de elaboração de escalas psicológicas. Revista de Psiquiatria Clínica, v. 25, n. 5, p. 206-213, 1998.

PIMENTEL, S. C. Formação de professores para a inclusão: Saberes necessários e percursos formativos. in: MIRANDA, T. G.; GALVAO FILHO, T. A. O professor e a Educação Inclusiva: formação, práticas e lugares. Salvador: EDUFBA, 2012.

PRIMO, A. Interação mediada por computador: comunicação, cibercultura, cognição. 3 ed. Porto Alegre: Sulina, 2011.

REA, L. M; PARKER, R. A. Metodologia de pesquisa: do planejamento à execução. São Paulo: Editora Pioneira, 2000.

REGO, T. C. Vygotsky: uma perspectiva histórico-cultural da educação: Petrópolis RJ: Vozes, 1995.

ROS, S. Z. Pedagogia e mediação em Reuven Feuerstein: o processo de mudança em adultos com história de deficiência. São Paulo: Plexus Editora, 2002.

SOUZA, A. M. M.; DEPRESBITERIS, L.; MACHADO, O. T. M. A mediação como princípio educacional: bases teóricas das abordagens de Reuven Feuerstein. São Paulo: Editora Senac São Paulo, 2003.

TÉBAR, L. O perfil do professor mediador: pedagogia da mediação. Trad. Priscila Pereira Mota. São Paulo: Editora SENAC, São Paulo, 2011.

UNESCO. Informe mundial sobre la Educación. Los docentes y la enseñanza en el mundo en mutación. Madri: Unesco/Santillana, 1998.

VYGOTSKI, L. S. A formação Social da Mente. COLE, Michael et al (Organizadores) 4 ed. São Paulo: Martins Fontes, 1991. 


\section{-

ISSN: 1984-6444 | http://dx.doi.org/10.5902/1984644434189

\section{Correspondência}

Miriam Bastos Reis Maia Lima - Mestre pelo Instituto Federal do Amazonas, Manaus, Amazonas, Brasil.

Elaine Maria Bessa Rebello Guerreiro - Professora doutora do Instituto Federal do Amazonas, Manaus, Amazonas, Brasil.

Instituto Federal do Amazonas. Av. Sete de Setembro, 1975, Centro. CEP: 69020120, Manaus, Amazonas, Brasil.

E-mail: miriambastos@hotmail.com - elainembrg@gmail.com

Recebido em 06 de agosto de 2018

Aprovado em 07 de dezembro de 2018

\section{(c) (7) (8)}

The is work is licensed under a Creative Commons Attribution-NonCommercial 4.0 International (CC BY-NC 4.0) 